
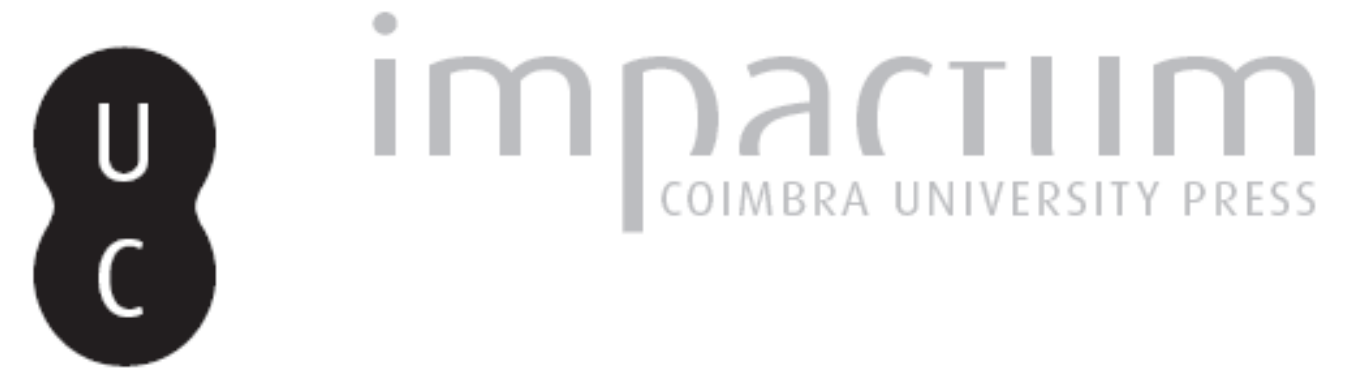

\title{
Vidros romanos do Museu de Castelo Branco
}

\section{Autor(es): $\quad$ Simões, Maria Helena}

Publicado por: Imprensa da Universidade de Coimbra

URL persistente:

URI:http://hdl.handle.net/10316.2/45615

DOI:

DOI:https://dx.doi.org/10.14195/1647-8657_25_9

Accessed : $\quad$ 26-Apr-2023 14:22:54

A navegação consulta e descarregamento dos títulos inseridos nas Bibliotecas Digitais UC Digitalis, UC Pombalina e UC Impactum, pressupõem a aceitação plena e sem reservas dos Termos e Condições de Uso destas Bibliotecas Digitais, disponíveis em https://digitalis.uc.pt/pt-pt/termos.

Conforme exposto nos referidos Termos e Condições de Uso, o descarregamento de títulos de acesso restrito requer uma licença válida de autorização devendo o utilizador aceder ao(s) documento(s) a partir de um endereço de IP da instituição detentora da supramencionada licença.

Ao utilizador é apenas permitido o descarregamento para uso pessoal, pelo que o emprego do(s) título(s) descarregado(s) para outro fim, designadamente comercial, carece de autorização do respetivo autor ou editor da obra.

Na medida em que todas as obras da UC Digitalis se encontram protegidas pelo Código do Direito de Autor e Direitos Conexos e demais legislação aplicável, toda a cópia, parcial ou total, deste documento, nos casos em que é legalmente admitida, deverá conter ou fazer-se acompanhar por este aviso.

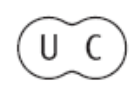


FACULDADE DE LETRAS

INSTITUTO DE ARQUEOLOGIA

CONIMBRIGA

$V O L U M E X X V$

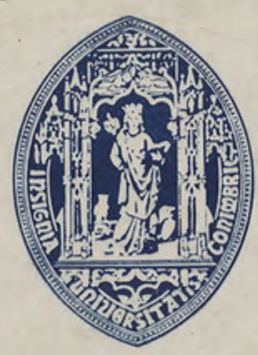

UNIVERSIDADE DE COIMBRA

1986 
MARIA HELENA Sim Ões

Professora do Ensino Secundário

VIDROS ROMANOS DO MUSEU DE CASTELO BRANCO

«Conimbriga», XXV p. (1986), 143-152

Rесимо o: os vidros que publicamos neste artigo constituem o espólio de $\backslash$ Tidros romanos que o Museu de Francisco Tavares Proença Júnior tem vindo a recolher ao longo dos anos. São fruto de achados ocasionais, oferta de particulares interessados na conservação do património local.

Apesar dos esforços desenvolvidos pelos responsálreis do Museu, as informações que sobre as peças possuímos são escassas e imprecisas. São em número de dez as peças que estudamos, entre garrafas, unguentários, taças e contas de colar. Os fragmentos restantes, por suas exíguas dimensões, não permitem estudo.

Résumé : Les verres publiés dans cet article constituent la collection de verres romains que le Musée de Francisco Tavares Proença Júnior (Castelo Branco, Portugal) a recueilli tout au long des années, resultat de trouvailles fortuites, d'offrandes de particuliers intéréssés à la présérvation du patrimoine local.

Malgré des efforts déployés par les responsables de ce musée, les renseignements sont insuffisants et imprécis. Les pièces que nous venons d'étudier - bouteilles, balsamaires, coupes et petites perles à collier - ne sont que dix. Les fragments qui restent, par leur petitesse, ne permettent pas fétude. 
(Página deixada propositadamente em branco) 


\section{VIDROS ROMANOS DO MUSEU DE CASTELO BRANCO (')}

\section{Garrafas}

As garrafas prismáticas do tipo Isings 50a, sopradas em molde, datam de meados do século i, embora se avente a hipótese de o seu fabrico se ter iniciado mais cedo ( ${ }^{2}$ ). Esta forma perdurou ao longo dos tempos, embora os exemplares dos séculos $\mathrm{m}$ e iv sejam em muito menor número e feitos num vidro delgado de fraca qualidade. No seu fabrico ter-se-iam usado moldes de madeira em cujo fundo se traçava uma composição geométrica ou figurativa, como marca de fabrico ou por meras razões de ordem estética.

Em Portugal são frequentes as garrafas decoradas e muito variada a temática utilizada (3). No Museu Nacional de Arqueologia e Etnologia (Lisboa), sob o número de inventário 13725 , proveniente de Galveias (Ponte de Sor), encontra-se uma garrafa semelhante ao nosso exemplar $\mathrm{n} .{ }^{\circ} \quad 1 \quad\left({ }^{4}\right)$, possivelmente fabricada a partir do mesmo molde.

Para a garrafa n. ${ }^{\circ} 2$ não conhecemos em Portugal paralelo algum. Numa garrafa existente no Museu Provincial de Bonne-

(x) Agradecemos ao Dr. António Salvado, Director do Museu, a autorização para estudarmos e publicarmos estes vidros.

Os desenhos são da autoria do Dr. José Luís Madeira e as fotos de José Carlos Martins Caetano.

(2) ISINGS 1957, p. 64.

(3) Alarcão 1975, p. 47-53.

(4) AlarCão 1975, n. ${ }^{\circ} 27$. 
fanten, sob o n. ${ }^{\circ}$ de inventário 1-19 $\left(^{5}\right)$ e numa outra, proveniente de uma sepultura de Gucuron ( $\left.{ }^{6}\right)$, podemos observar uma decoração semelhante, ainda que apresentando apenas um círculo.

Quanto ao exemplar n. ${ }^{\circ}$, trata-se de um fragmento de fundo de uma grande garrafa moldada, Isings 50 ou 51, com decoração em relevo, possivelmente semelhante a exemplares encontrados em Conimbriga ( ${ }^{7}$ ). No entanto, a exiguidade do fragmento não nos permite reconstituir a decoração.

\section{Unguentarios}

O unguentário n. ${ }^{\circ}$, em forma de castiçal, pode ser incluído no tipo Isings $82 \mathrm{~B} 2$.

Trata-se de uma peça soprada que se situa cronologicamente

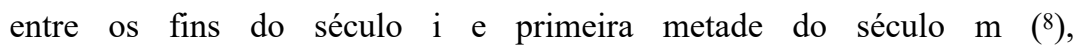
embora para o Oriente a datação proposta se estenda entre a segunda metade do século $n$ e séculos m e iv d.C. $\left({ }^{9}\right)$.

Em Portugal encontramos alguns unguentários deste tipo $\left({ }^{\mathrm{x} 0}\right)$. Proveniente de Escalos de Cima (Castelo Branco), foi publicado por Leite de Vasconcellos um unguentário do tipo do nosso ${ }^{(\mathrm{u})}$.

$\mathrm{O}$ unguentário $\mathrm{n} .{ }^{\circ}$ 5, um aríbalo de asa delfiniforme que podemos incluir no tipo Isings 61 , situa-se cronologicamente entre os séculos i e iv e pode apresentar grande variedade de perfis. ${ }^{(\cdot)}$

(•) ISINGS 1971, p. 29, n. ${ }^{\circ} 95$.

(') Dumoulin 1962, fase. 1, p. 328 b.

(') Alarcão 1976(1), p. 221, n. ${ }^{\circ} 65$ e 66.

( $\left.{ }^{8}\right)$ ISINGS 1957, p. 99.

(9) VESSBERG 1956, p. 59.

(10) Alarcão 1965, p. 99, n. ${ }^{\circ}$ 161; Alarcão 1976(1), p. 163, n. ${ }^{\circ} 41$; Alarcão 1968(2), p. 82-83, n. 5 e 6; Alarcão 1966(2), p. 5-12, n. ${ }^{\circ}$ 7; Alarcão 1968(1), p. 12, n. ${ }^{\circ}$ 9; Alarcão 1970, p. 252, n.0 42-45; Alarcĩo 1971(1), p. 198, n. 17 e nota 13; Alarcĩo 1963(2), p. 369-370, n. ${ }^{\circ} 3$ e p. 375-376, n. ${ }^{\circ} 10$; Alarcão 1964, p. 91, n. ${ }^{\circ} 15$; Alarcão 1967, p. 25, n. ${ }^{\circ}$ 54; Alarcão 1966(1), p. 141; Alarcão 1974, p. 15, sepultura 35; Alarcão 1971(2), p. 27, n. ${ }^{\circ}$ 15; Delgado 1984, p. 182, n. ${ }^{\circ} 11$ e 12; AlarCão 1978(1), p. 106, n. ${ }^{\circ} 20$.

( ${ }^{n}$ Leite de VASCONCellos 1918, p. 3, fig. 11. 
A forma deste vidro soprado aparece a imitar peças metálicas ou cerâmicas e é muito comum (12). Em território nacional este tipo aparece documentado em Torres Novas (13), na Citânia de Briteiros $\left({ }^{14}\right)$ e em Gonimbriga $\left({ }^{15}\right)$. De referir ainda a existência de um exemplar de proveniência desconhecida, de posse do Museu Nacional de Arqueologia e Etnologia (Lisboa) (16).

Taças

Apesar das suas reduzidas dimensões, o fragmento n. ${ }^{\circ} 6$ parece pertencer a uma taça, soprada em molde, de copa arqueada, quebrada nos ombros e colo contracurvado.

Este tipo é frequente no Oriente mas raro nas províncias ocidentais. No Ocidente aparece em Londres, Camulodunun, Verulamium, Elvage-les-Hovelange, Vindonissa, Aquileia e Mérida (17). Berger apresenta um exemplar, possivelmente da Anatólia Ocidental, afirmando ter sido esta forma de fabrico post-flaviano, aparecendo até aos fins do século i $\left({ }^{18}\right)$, em duas variantes, uma mais baixa, com nervuras horizontais na parte inferior da pança, e outra, mais alta e sem nervuras.

Entre nós o tipo é raro. Alarcão publicou dois exemplares de Conimbriga ( $\left.{ }^{19}\right)$.

A taça n. ${ }^{\circ} 7$, em vidro decorado com fios relevados, usou-se do século i ao século v d.C. $\left({ }^{20}\right)$, em grande varidade de formas ${ }^{(21)}$. Por esta razão e pelas pequenas dimensões do fragmento, não nos é possível definir a forma da peça.

(«) ISINGS 1957, p. 78-81.

(13) Alarcão $1963(2)$, p. $370,{ }^{\circ}{ }^{\circ}$.

(14) AlarCão 1963(1), p. 195, n. ${ }^{\circ} 22$.

(15) Alarcão 1976(1), p. 170, n. ${ }^{\circ}$ 83; Alarcão 1965, p. 54, n. ${ }^{\circ} 67-70$.

(16) AlarCão $1976(2)$, p. 57, n. ${ }^{\circ} 9$.

(17) Alarcĩo 1976(1), p. 167.

(18) Berger in Alarcão, op. cit. supra.

(19) Alarcão 1965, p. 29, n. ${ }^{\circ} 17$; Alarcĩo 1976(1), p. 167, n. ${ }^{\circ} 43$.

(20) Alarcão 1965, p. 26.

(21) AlarCão 1964, p. 99. 
Fremersdorf $\left({ }^{22}\right)$ publicou dois exemplares que, ainda que não reproduzam exactamente a decoração do nosso pequeno fragmento, apresentam o mesmo tipo de vidro. De referir que esta decoração se obtinha pela aplicação de um fio de vidro sobre a peça ainda quente. Os resultados da aplicação desta técnica pode revestir o aspecto de cordões serpentiformes, desenhos ondulados, oitos e forquilhas.

Em território nacional este tipo de decoração é frequente, surgindo em formas muito variadas (®)).

Também frequente no nosso país é o tipo da taça n. ${ }^{\circ} 8$, soprada, de copa arqueada e bordo engrossado ao fogo $\left({ }^{24}\right)$. Em Conimbriga estas taças constituem o grupo mais abundante de vidros romanos e nele Alarcão distingue cinco perfis cuja cronologia discute ${ }^{(25)}$. O nosso fragmento é tão exíguo que não permite que o integremos em qualquer perfil.

Contas de colar

As contas de colar anelares, em forma de «rodilha», eram obtidas pelo enrolamento de um grosso fio de vidro em volta de uma vara. Esta técnica foi utilizada em todas as épocas e, portanto, não nos fornece qualquer informação cronológica ${ }^{(26)}$.

(22) FREMERSDORF 1959, estampas 36 e 37.

(23) Alarcão 1976(1), p. 226, n. ${ }^{\circ} 179$ a 182; AlARCÃo 1965, p. 26, n. ${ }^{\circ} 12$ a 15; ALARCÃO 1964, p. 97-102, n. ${ }^{\circ} 24$ a 26; ALARCÃO 1966(1), p. 57, n. ${ }^{\circ} 3$; AlARCão 1978(2), p. 159, n. ${ }^{\circ} 39$ a 41; AlARCÃo 1984, p. 176, n. ${ }^{\circ}$; AlARCÃo $1968(1)$, p. 27, n. ${ }^{\circ} 45$ e p. 36, n. ${ }^{\circ} 70$.

j24) Pereira 1970, p. 371; Alarcão 1965, p. 118; Alarcão 1970, p. 241; AlARCÃo 1963(2), p. 381-386; AlARCÃo 1964, p. 105; AlARCão 1971(2),

p. 32; ALARCÃO $1963(1)$, p. 205, n. 34.

(23) AlARCÃo 1976(1), p. 193-195.

(26) AlARCÃo 1976(1), p. 211. 


\section{CATÁlOGO}

1. Garrafa. Vidro transparente verde-gelo com bolhas de ar, impurezas negras e ligeira escuma. Pedra, especialmente no bordo e asa. Picada e riscada pelo uso. Concreções calcárias. Ranhura funda cortando toda a espessura do colo.

Bordo partido e incompleto.

Corpo de secção quadrada, ombros altos e arredondados, gargalo ligeiramente tronco-cónico. Bordo repuxado para fora e revirado sobre si mesmo, achatado na parte superior.

Asa larga, multinervurada na sua face externa, presa ao ombro. Base ligeiramente côncava, relevada, com um hexafólio inscrito em quatro círculos concêntricos. $\mathrm{O}$ círculo externo não está completo pois o seu perímetro ultrapassa as dimensões da base.

Altura: $164 \mathrm{~mm}$.

$088 \mathrm{~mm}$.

Proveniência: Sobreira Formosa (Castelo Branco).

N. ${ }^{\circ}$ de inventário: 43.9.

2. Garrafa. Vidro transparente verde-gelo com bolhas de ar (no gargalo as bolhas são grandes e oblongas). Pedra no gargalo e asa.

Muito picada e riscada pelo uso. Concreções calcárias.

Inteira e intacta.

Corpo de secção quadrada, ombros altos e arrendondados. Gargalo cilíndrico, estrangulado na base. Bordo repuxado para fora e depois revirado sobre si mesmo, achatado na parte superior.

Asa multinervurada. Base relevada com dois círculos concêntricos, no menor dos quais está inscrito um trifolio.

Altura: $155 \mathrm{~mm}$.

0 maior: $85 \mathrm{~mm}$.

0 do lábio: $55 \mathrm{~mm}$.

Proveniência: Sobreira Formosa (Castelo Branco).

$\mathrm{N} .^{\circ}$ de inventário: 43.10.

3. Fragmento de fundo de garrafa, ligeiramente côncavo, relevado com motivos geométricos e pérolas.

Vidro transparente verde-gelo, muito picado e riscado pelo uso. Espessura: $8 \mathrm{~mm}$.

Proveniência: Sant'Ana (Castelo Branco).

N. ${ }^{\circ}$ de inventário: 81.49 .

4. Unguentário. Vidro verde-gelo com bolhas de ar circulares e oblongas, com estrias de soflagem e pedra. Concreções calcárias.

Completo e intacto.

Conimbriga, 25 (1986), 143-152 
Gargalo alto, cilíndrico, que se alarga um pouco na base. Marcas de modelação na base.

Reservatório baixo, com base recta.

Bordo arredondado ao fogo.

Marca de pontel visível na base.

Altura: $85 \mathrm{~mm}$.

0 máximo: $75 \mathrm{~mm}$.

0 gargalo: $19-24 \mathrm{~mm}$.

Proveniência: Sobreira Formosa (Castelo Branco).

N. ${ }^{\circ}$ de inventário: 29.40 .

5. Unguentário. Fragmento de gargalo, parte do corpo e uma asa.

Vidro verde-gelo com bolhas de ar oblongas e impurezas negras.

Picado e riscado pelo uso. Concreções calcárias.

Gargalo cilíndrico, curto, ligeiramente estrangulado na base.

Bordo repuxado para fora e revirado sobre si mesmo, achatado

na parte superior.

Asa delfiniforme. Corpo esférico.

Espessura do vidro no bojo: $2 \mathrm{~mm}$.

Altura da asa: $30 \mathrm{~mm}$.

Proveniência: Fonte Santa, Lousa (Castelo Branco).

N. ${ }^{\circ}$ de inventário: 80.141 .

6. Taça. Fragmento de fundo moldurado na parte inferior da pança.

Vidro translúcido verde-gelo com bolhas de ar, ligeiramente riscado

e picado. Base côncava.

Espessura: $5 \mathrm{~mm}$.

Proveniência: S. Martinho (Castelo Branco).

N. ${ }^{\circ}$ de inventário: 77.146.

7. Taça. Fragmento da copa. Vidro transparente, incolor, muito irisado, com irisão leitosa.

Parede convexa, decorada com fios de vidro grosso, também incolores, pouco relevados na parte superior mas muito grossos na parte inferior.

Espessura: $3 \mathrm{~mm}$.

Proveniência: Castelo (Castelo Branco).

$\mathrm{N} .^{\circ}$ de inventário: 10.724 .

8. Taça. Fragmento de bordo em vidro transparente verde-musgo.

Bordo espessado ao fogo, em forma de cabeça de fósforo.

Riscado e ligeiramente irisado. Parede rectilínia.

Espessura no bordo: $4 \mathrm{~mm}$.

Espessura da parede: $1 \mathrm{~mm}$.

Proveniência: Fonte da Bica, Escalos de Cima (Castelo Branco).

N. ${ }^{\circ}$ de inventário: 77.187. 
9. Conta de colar hexagonal.

Vidro verde-sombra.

Altura: $11 \mathrm{~mm}$.

$07 \mathrm{~mm}$.

Proveniência: S. Martinho (Castelo Branco).

N. ${ }^{\circ}$ de inventário: 77.150 .

10. Conta de colar anelar.

Vidro verde-água, ligeiramente picado e riscado.

Altura: $3 \mathrm{~mm}$.

$09 \mathrm{~mm}$.

Proveniência: S. Martinho (Castelo Branco).

N. ${ }^{\circ}$ de inventário: 77.151.

\section{BIBLIOGRAFIA}

Alarcão 1963(1)-J. e A. Alarcão, Vidros Romanos do Museu de Martins Sarmento, in «Revista de Guimarães», vol. LXXIII, n. ${ }^{\circ}$ 1-2, Jan.-Jun. 1963.

Alarcão 1963(2)-J. e A. Alarcão, Quatro Pequenas Colecções de Vidros Romanos, in «Revista de Guimarães», vol. LXXIII, n. ${ }^{\circ}$ 3-4, Jul.-Dez. 1963.

Alarcão 1964-J. e A. Alarcão, Vidros Romanos do Museu Municipal da Figueira da Foz, in «Revista de Guimarães», vol. LXXIV, n. ${ }^{\circ} 1-2$, Jan.-Jun. 1964.

Alarcẽo 1965-J. e A. Alarcĩo, Vidros Romanos de Conimbriga, 1965.

Alarcão 1966(1) - J. e A. Alarcão, O Espólio da Necrópole de Valdoca, in «Conimbriga», $\mathrm{V}, 1966$.

Alarcão 1966(2)-J. e A. Alarcão, Sepultura Luso-Romana descoberta no

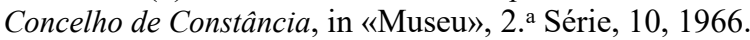

Alarcão 1967-J. e A. Alarcão, Vidros Romanos do Museu Arqueológico de Vila Viçosa, in «Conimbriga», VI, 1967.

Alarcão 1968(1)-J. Alarcĩo, Vidros Romanos de Museus do Alentejo e Algarve, in «Conimbriga», VII, 1968.

Alarcão 1968(2)-J. Alarcão, Espólio de uma Sepultura Luso-Romana de Pombalinho, Santarém, in «O Arqueólogo Português», Série III, vol. II, 1968.

Alarcão 1970-J. Alarcão, Vidros Romanos de Balsa, in «O Arqueólogo Português»), 3. a Série, IV, 1970.

Alarcão 1971(1 )-J. Alarcão, Vidros Romanos de Aramenha e Mértola, in «O Arqueólogo Português», Série III, vol. v, 1971. 
Alarcão 1971(2)-J. Alarcão, Mais Algumas Pequenas Colecções de Vidros Romanos, in «Conimbriga», X, 1971.

Alarcão 1974-J. e A. Alarcão, A Necrópole de Monte Farrobo (Aljustrel), in «Conimbriga», XIII, 1974.

Alarcão 1975-J. Alarcĩo, Bouteilles Carreès au Fond Décoré du Portugal Romain, J. G. S., XVII, 1975.

Alarcão 1976(1)-J. Alarcão, Verres in J. Alarcão e R. Étifnne, Fouilles de Conimbriga VJ, Céramiques Diverses et Verres, Paris, 1976.

Alarcão 1976(2)-J. Alarcĩo, Vidros Romanos provenientes da colecção do Rei D. Manuel, in «Conimbriga», XV, 1976.

Alarcĩo $1978(1)$ - J - Alarcẽo, Vidros Romanos do Alentejo no Museu Nacional de Arqueologia (Lisboa), in «Conimbriga», XVII, 1978.

Alarcão 1978(2)-J. Alarcão, Vidros do Castelo de Alcácer do Sal, in «Setúbal Arqueológica», vol. IV, Setúbal, 1978.

Alarcão 1984-J. Alarcão, Sete Jarros de Vidro Romanos, in «Lucerna», Homenagem a D. Domingos de Pinho Brandão, Porto, 1984.

Delgado 1984-M. Delgado, Sepultura Romana encontrada junto ao Largo Carlos Amarante - Rraga, in «Lucerna», Homenagem a D. Domingos de Pinho Brandão, 1984.

Dumoulin 1962-A. Dumoulin, Les Fosses Funéraires de Cucuron (Vaucluse), in «Gallia», XX, 1962.

Fremersdof 1959-F. Fremersdorf, Rõmische Glaser mit Fadenauflage in Kòln, Colónia, 1959.

I sings 1957-C. Isings, Roman Glass From Dated Finds, Groningen, 1957.

IsINGs 1971-C. Is Ings, Roman Glass in Limburg, Groningen, 1971.

Leite de Vasconcellos 1918-J. Leite de Vasconcellos, Antigualhas da Beira Baixa. 2. Objectos Romanos de Escalos de Cima, in «O Archeologo Português»», XXIII, 1918.

Pereira 1970-M. A. Horta Pereira, Monumentos Arqueológicos do Concelho de Mação, Mação, 1970.

vessmerg 1956-vessmerg, The Swedish Cyprus Expedition, vol. IV, Part 3 — The Hellenistic and Roman Periods in Cyprus, Estocolmo, 1956. 


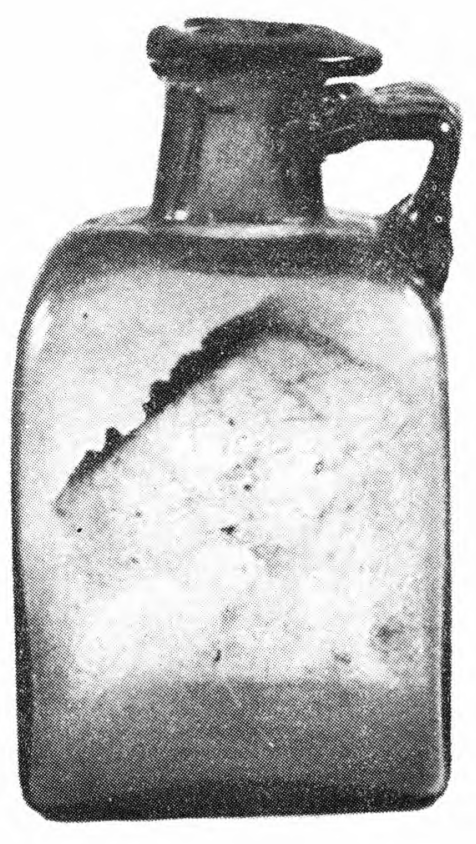

1

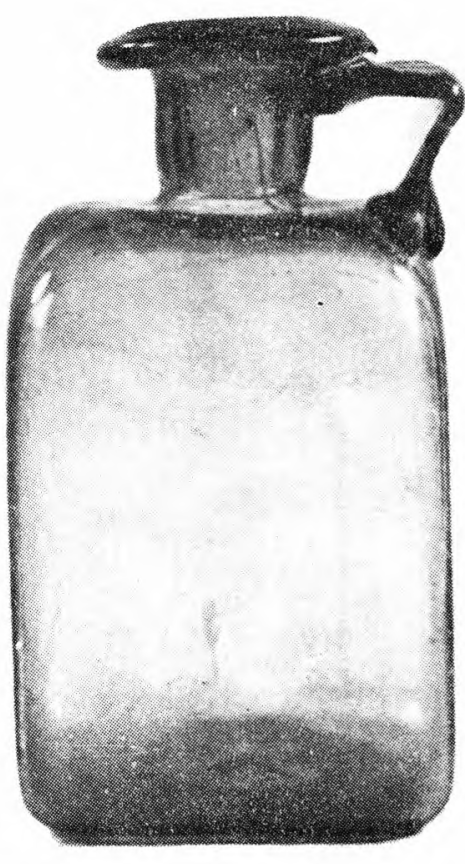

2

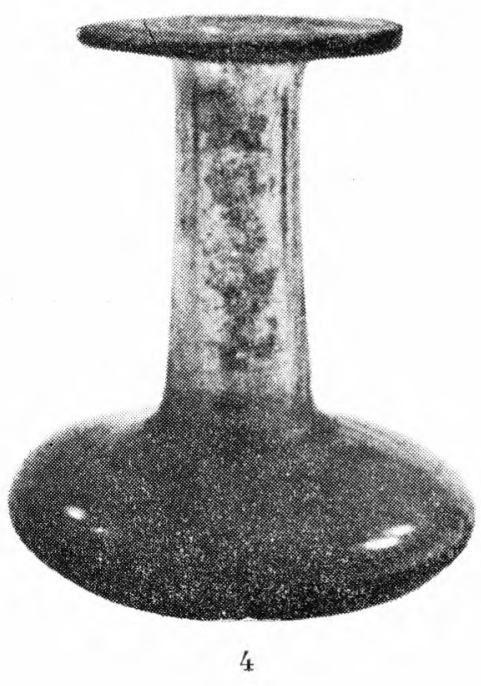



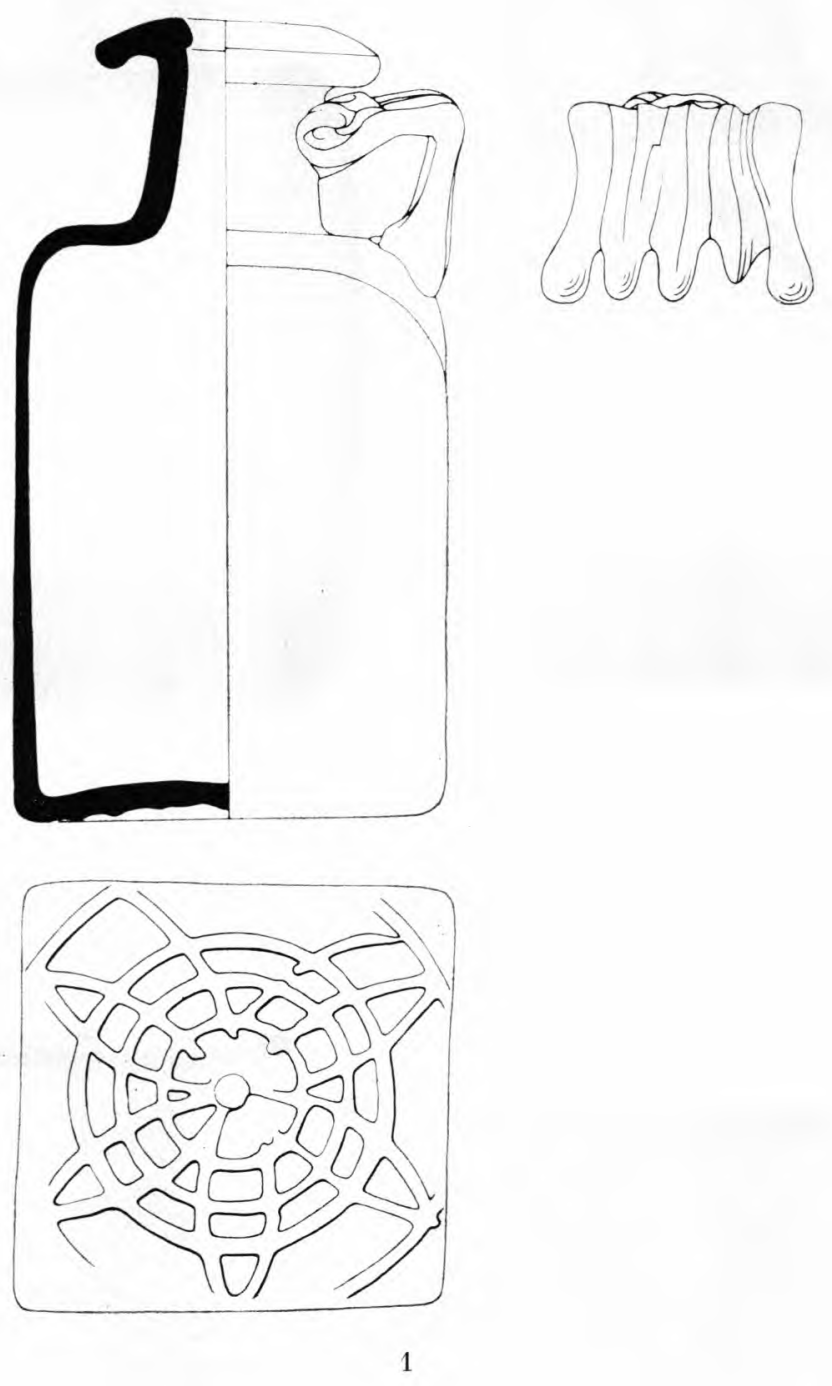

Esc. $1: 2$ 

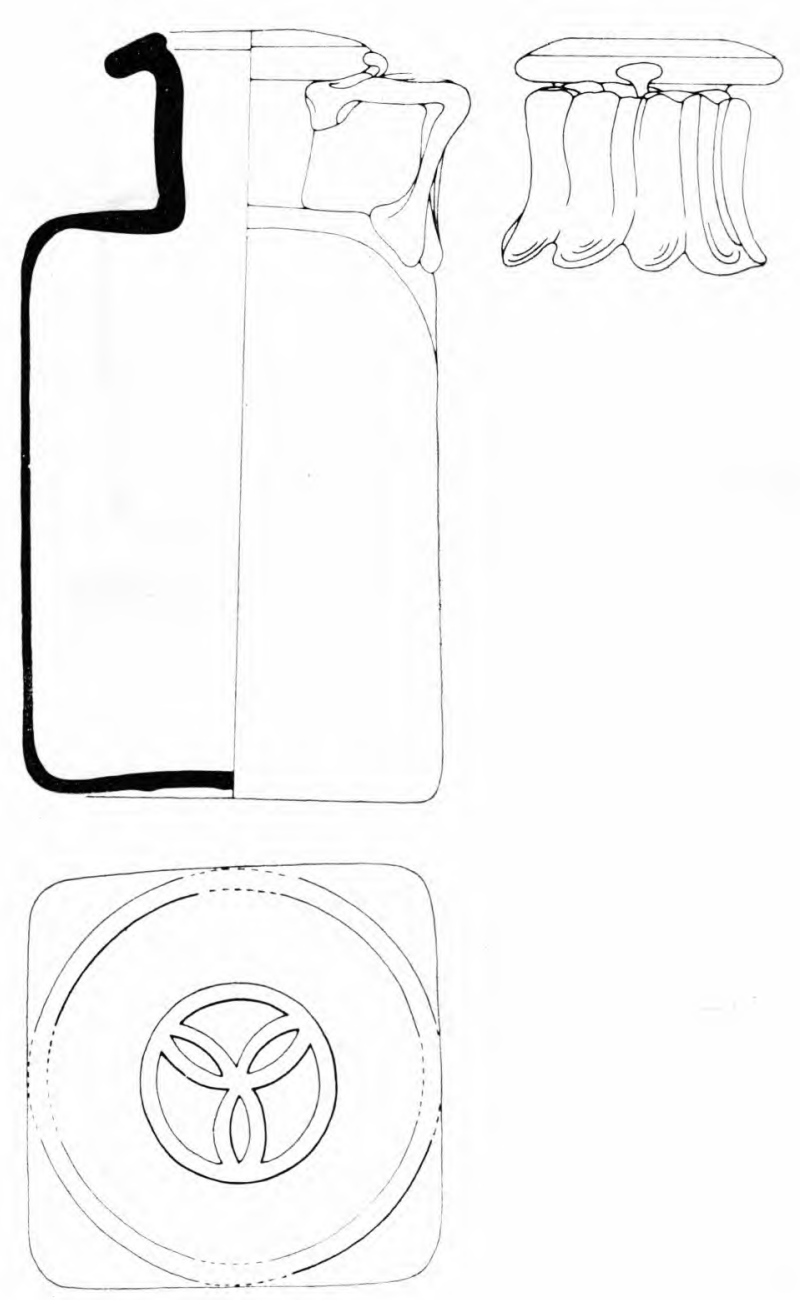

2

Esc. 1:2 


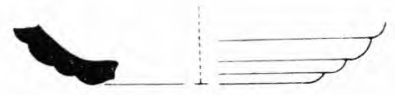

6
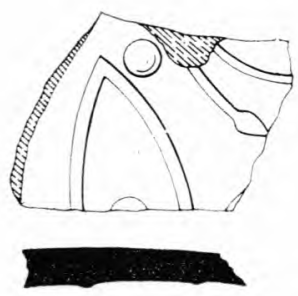

3
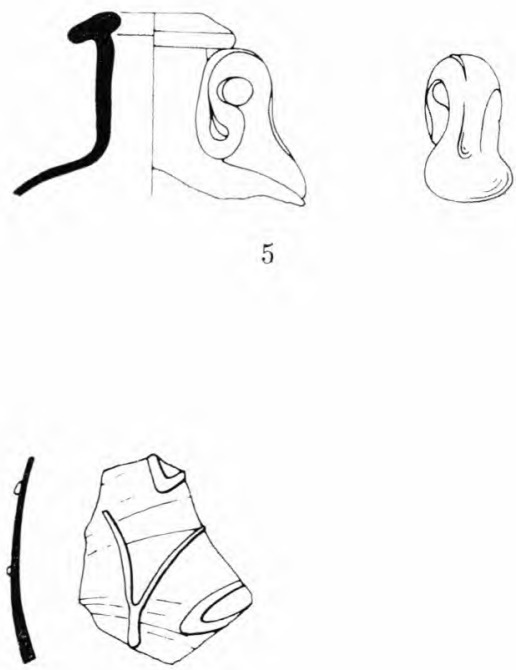

7

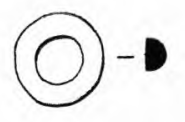

10

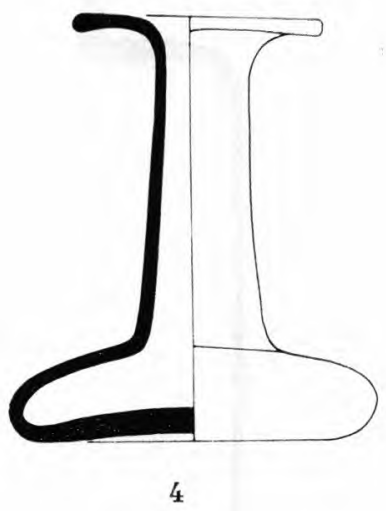

(20)

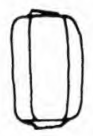

9

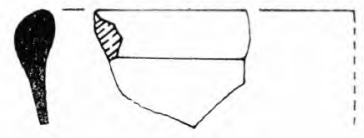

8

N.os 3, 4, 5, 6 e 7: Esc. $1: 2$;

n. os 8,9 e 10: Esc. 1:1 